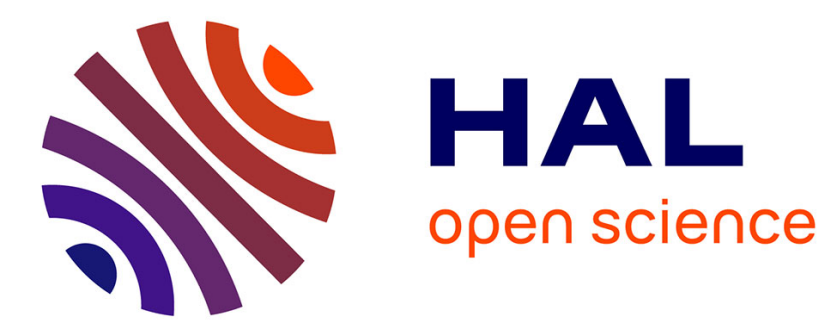

\title{
Premiers écrits philosophiques. Productivité conceptuelle et créativité rédactionnelle du CE2 au CM2
}

Emmanuèle Auriac-Slusarczyk, Cathy Thebault, Bernard Slusarczyk, Marie France Daniel, Julie Pironom

\section{- To cite this version:}

Emmanuèle Auriac-Slusarczyk, Cathy Thebault, Bernard Slusarczyk, Marie France Daniel, Julie Pironom. Premiers écrits philosophiques. Productivité conceptuelle et créativité rédactionnelle du CE2 au CM2. Bulletin de psychologie, 2018, 71-3 (555), pp.671-690. halshs-01683725

\section{HAL Id: halshs-01683725 \\ https://shs.hal.science/halshs-01683725}

Submitted on 14 Jan 2018

HAL is a multi-disciplinary open access archive for the deposit and dissemination of scientific research documents, whether they are published or not. The documents may come from teaching and research institutions in France or abroad, or from public or private research centers.
L'archive ouverte pluridisciplinaire HAL, est destinée au dépôt et à la diffusion de documents scientifiques de niveau recherche, publiés ou non, émanant des établissements d'enseignement et de recherche français ou étrangers, des laboratoires publics ou privés. 


\title{
Premiers écrits philosophiques. Productivité conceptuelle et créativité rédactionelle du CE2 au CM2
}

\author{
Slusarczyk Emmanuèle a \\ Thebault Cathy ${ }^{\text {a }}$ \\ Slusarczyk Bernard ${ }^{\text {a }}$ \\ Daniel Marie-France ${ }^{b}$
}

Pironom Julie ${ }^{a}$

a Université Clermont Auvergne, ACTé, F-63000 Clermont-Ferrand, France.

${ }^{\mathrm{b}}$ Groupe de recherche sur l'éthique et l'éducation éthique, GREE, Université de Montréal, Québec, Canada.

Correspondance : Emmanuèle Auriac-Slusarczyk, Université Clermont Auvergne, École supérieure du professorat et de l'éducation, 34 avenue Jean-Jaurès, CS20001, 63407 Chamalières, France.

Courriel : emmanuele.auriac@uca.fr

Texte reçu le 13 juin 2017 et accepté le 6 novembre 2017

Résumé : La qualité rédactionnelle est étudiée sur un échantillon de 167 copies d'élèves. Les élèves produisent des brouillons et des textes. À partir de variables philosophique, cognitive et linguistique, les consignes croisant trois thèmes - nature/culture, rêve et liberté - avec deux supports - œuvres d'art et magazine - sont testées. Les élèves sont aptes dès le CM1 à produire significativement des postulats, puis des exemples, et démarrent la production de raisonnements et d'hypothèses, révélant des performances philosophiques. L'évolution développementale de la conceptualisation est significative du CE2 au CM2. Mobiliser des distinctions conceptuelles, organiser son brouillon dépendent significativement de la consigne. Mobiliser la pensée divergente ou des métaphores concerne peu d'élèves. Un effet de sexe confirme la supériorité des filles. L'étude engage à varier les consignes d'écriture à l'école primaire.

Early philosophical writings. Conceptual written productivity and creativity from eight to eleven Abstract: The written quality is studied onto a sample of 167 copying writings. The students are producing drafts and texts. From philosophical, cognitive and linguistics variables, topics - nature/culture, dream and liberty crossed mediums - art and magazine - are tested. The students produce after the fourth grade (CM1) significantly assumptions, and examples, and begin production of reasoning and hypothesis, as considered as philosophical capacities. Developmental progresses significantly change from CE2 (third grade) to CM2 (five grade). Conceptual distinctions and drafts organization depend significantly from instructions. Divergent thinking or metaphors don't cover many students. Gender effect confirms girls' greater proficiency. The study involves under varying instructions at primary school.

Voir le fichier complet après la parution prévu au Bulletin de psychologie n 42018 
